\title{
Microstructure of mullite-zirconia fibres grown by directional solidification
}

\author{
R. G. Carvalho*, M. S. Pires*, A. J. S. Fernandes*, F. J. Oliveira**, T. Monteiro*, R. F. Silva**, F. \\ M. Costa** \\ * I3N, Department of Physics, University of Aveiro, Campus de Santiago, 3810-193 Aveiro, Portugal \\ ** CICECO, Department of Ceramic and Glass Engineering, University of Aveiro, Campus de \\ Santiago, 3810-193 Aveiro, Portugal
}

Recently, much attention has been given to directional solidified eutectic (DSE) materials for functional and structural applications [1]. DSE materials take advantage from their microstructural features. Typically, DSE are dense homogeneous materials composed by fine microstructures without grain boundaries (GBs). Since impurities and defects typically concentrate at GBs, their deleterious effects on the mechanical, thermal and electrical properties can thus be minimized [1].

Mullite $\left(2 \mathrm{Al}_{2} \mathrm{O}_{3} \cdot \mathrm{SiO}_{2}\right)$ is a well known refractory material with a high melting point $\left(\sim 1830{ }^{\circ} \mathrm{C}\right)$, processable by directional solidification methods as laser floating zone (LFZ), Czochralski and internal crystallization $[2,3]$. However, mullite shows a low fracture toughness value $\left(2.5 \mathrm{MPa} \cdot \mathrm{m}^{0.5}\right)$, at room temperature [2]. In order to surpass this problem, additions of a second phase have been suggested, namely zirconia - $\mathrm{ZrO}_{2}$ [4]. Hence, the purpose of this first study is to investigate the microstructure dependence on the processing variables (composition and growth rate) for the mullitezirconia system.

Fibres of mullite-YSZ (yttria stabilized zirconia) were produced according with the eutectic (E1 - 30 $\%$ wt $\mathrm{ZrO}_{2}, 20 \%$ wt $\mathrm{SiO}_{2}, 50 \%$ wt $\mathrm{Al}_{2} \mathrm{O}_{3}$ ) and off-eutectic (E2 - $67 \%$ wt $\mathrm{ZrO}_{2}, 10 \%$ wt $\mathrm{SiO}_{2}, 23 \%$ wt $\mathrm{Al}_{2} \mathrm{O}_{3}$; $\mathrm{E} 3-16 \%$ wt $\mathrm{ZrO}_{2}, 24 \% \mathrm{wt} \mathrm{SiO}_{2}, 60 \% \mathrm{wt} \mathrm{Al}_{2} \mathrm{O}_{3}$ ) compositions using LFZ. The growth was conducted in atmospheric conditions, with pulling rates from 10 to $500 \mathrm{~mm} / \mathrm{h}$. The fibres, with $\sim 1.40$ $\mathrm{mm}$ in diameter, were pulled downwards, in order to avoid the incorporation of gas bubbles in the solid and to obtain uniform dense materials. Mullite and zirconia with monoclinic and/or tetragonal structures were identified by X-ray diffraction (XRD). The zirconia tetragonal phase tends to predominate over the monoclinic one as the pulling rate increases, as observed in XRD and corroborated by visible Raman spectroscopy.

A detailed microstructure inspection of the eutectic and off-eutectic fibres was performed by scanning electron microscopy (SEM) coupled with energy dispersive spectroscopy (EDS). Their microstructural features were compared and related to the nominal composition and pulling rates. The eutectic composition shows mainly eutectic grains (Figure 1a, b) aligned with the growth axis with morphology changing from coupled eutectic structures to cellular eutectic with the increase of the growth rate. The formation of an amorphous phase composed by $\mathrm{Al}, \mathrm{Y}$ and $\mathrm{Si}$ at faster pulling rates was inferred from the EDS elemental distribution map, Figure 1. The off-eutectic composition with the least zirconia amount led to mullite and mullite-zirconia eutectic grains well aligned along the growth axis, as illustrated in Figure 1c. On the contrary, the richest $\mathrm{ZrO}_{2}$ composition originated a random orientation, Figure 1d.

\section{References}

1. Llorca, J. and V.M. Orera, Prog. in Mater. Science 51: 711-809, 2006

2. Schneider, H., J. Schreuer, B. Hildmann,. J. Eur. Ceramic Society 28: 329-344, 2008

3. Carvalho, R.G., et al., J. Eur. Ceramic Society 30: 3311-3318, 2010

4. Öztürk, C., Y.K. Tür, J. Eur. Ceramic Society 27: 1463-1467, 2007

5. Llorca, J. and V.M. Orera, Prog. in Mater. Science 51: 711-809, 2006

6. Schneider, H., J. Schreuer, B. Hildmann,. J. Eur. Ceramic Society 28: 329-344, 2008

7. Carvalho, R.G., et al., J. Eur. Ceramic Society 30: 3311-3318, 2010

8. Öztürk, C., Y.K. Tür, J. Eur. Ceramic Society 27: 1463-1467, 2007 


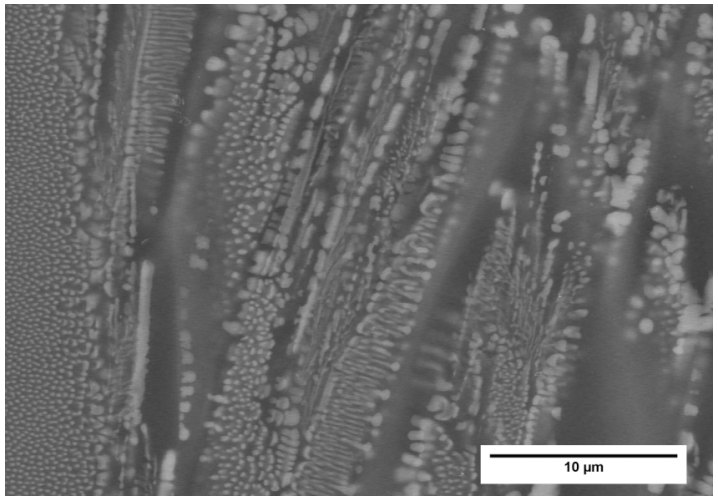

a.

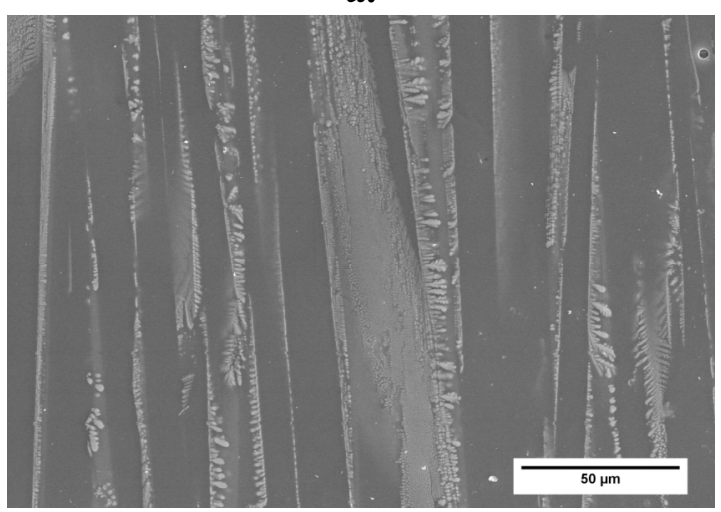

c.

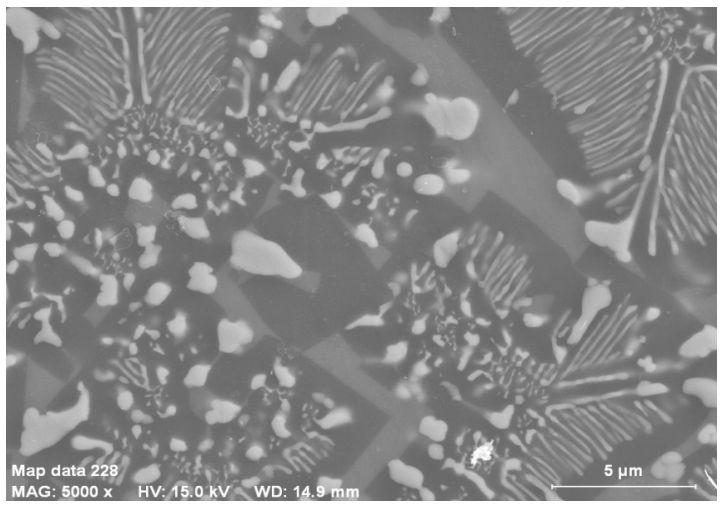

e.

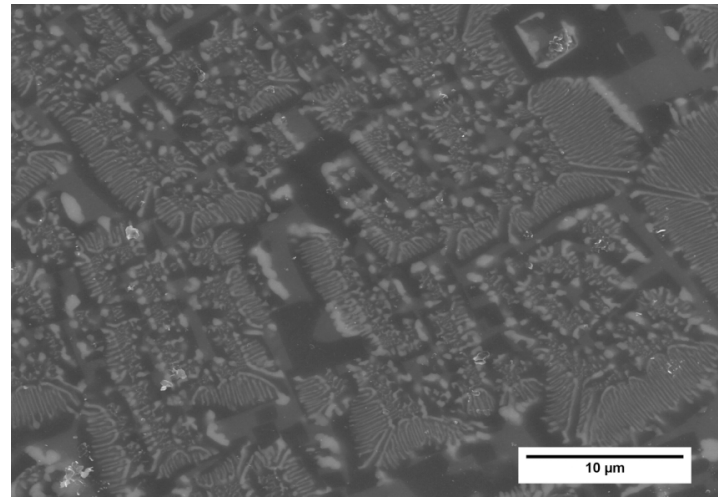

b.

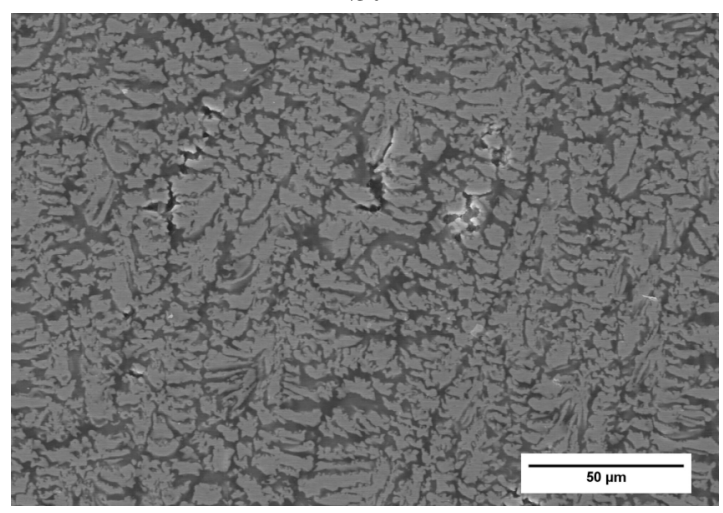

d.

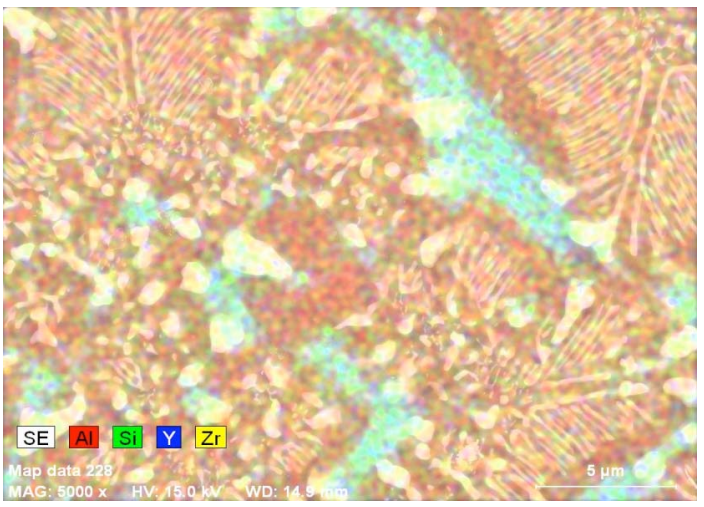

f.

Figure 1. Microstructures of mullite-zirconia fibres processed by the LFZ method at $100 \mathrm{~mm} / \mathrm{h}$. Micrographs $a$ and $b$ correspond to cross-sections of the eutectic composition in the longitudinal and transversal views, respectively. Micrographs $\mathrm{c}$ and $\mathrm{d}$ correspond to longitudinal cross-sections of the two off-eutectic $\mathrm{ZrO} 2$ poor and rich compositions, respectively. The f image corresponds to an EDS elemental chemical distribution map from the eutectic sample depicted in e. 